\title{
Posttranscriptional upregulation of HER3 by HER2 mRNA induces trastuzumab resistance in breast cancer
}

\author{
Xin $\mathrm{Li}^{1 *}$, Yuxiu Xu ${ }^{1 *}$, Yun Ding ${ }^{1}$, Changfei $\mathrm{Li}^{1}$, Hong Zhao ${ }^{2}$, Jiandong Wang ${ }^{3}$ and Songdong Meng ${ }^{1,4^{*}}$
}

\begin{abstract}
Background: HER2 gene amplification generates an enormous number of HER2 transcripts, but the global effects on endogenous miRNA targets including HER family members in breast cancer are unexplored.

Methods: We generated a HER2-3'UTR expressing vector to test the tumor-promoting properties in HER2 low expressing T47D and MCF7 cells. Through microarray analysis and real-time PCR analysis we identified genes that were regulated by HER2-3'UTR. Positive and negative manipulation of miRNA expression, response element mutational studies and transcript reporter assays were performed to explore the mechanism of competitive sequestration of miR125a/miRNA125b by HER2 3'UTR.

To investigate if trastuzumab-induced upregulation of HER3 is also mediated through miRNA de-repression, we used the CRISPR/cas9 to mutate the endogenous HER2 mRNA in HER2 over-expressing Au565 cells. Finally, we looked at cohorts of breast cancer samples of our own and the TCGA to show if HER2 and HER3 mRNAs correlate with each other.
\end{abstract}

Results: The HER2 3'UTR pronouncedly promoted cell proliferation, colony formation, and breast tumor growth. High-throughput sequencing revealed a significant increase in HER3 mRNA and protein levels by the HER2 3'untranslated region (3'UTR). The HER2 3'UTR harboring a shared miR-125a/b response element induced miR-125a/b sequestration and thus resulted in HER3 mRNA derepression. Trastuzumab treatment upregulated HER3 via elevated HER2 mRNA expression, leading to trastuzumab resistance. Depletion of miR-125a/b enhanced the antitumor activity of trastuzumab. Microarray data from HER2-overexpressing primary breast cancer showed significant elevation of mRNAs for predicted miR-125a/b targets compared to non-targets.

Conclusions: These results suggest that HER2 3'UTR-mediated HER3 upregulation is involved in breast cell transformation, increased tumor growth, and resistance to anti-HER2 therapy. The combinatorial targeting of HER3 mRNA or miR-125a/b may offer an effective tool for breast cancer therapy.

Keywords: HER2, HER3, miR-125a/b, Trastuzumab resistance, Breast cancer

\section{Background}

The HER-2/neu oncogene is amplified two-fold to $>20$-fold in approximately $25 \%$ of breast cancers. Overexpression or gene amplification of HER2 is associated with poor prognosis and an aggressive course of the disease, such as oncogenic transformation, tumorigenesis, and metastasis [1].

\footnotetext{
*Correspondence: lix@im.ac.cn; xuyuxiu16@mails.ucas.ac.cn; mengsd@im.ac.cn

${ }^{1}$ CAS Key Laboratory of Pathogenic Microbiology and Immunology, Institute of Microbiology, Chinese Academy of Sciences (CAS), Beijing, People's Republic of China

Full list of author information is available at the end of the article
}

HER2 belongs to the Type I receptor tyrosine kinase family, which includes four family members: EGFR (HER1), HER2 (neu or ERBB2), HER3, and HER4 [2]. In spite of possessing no known ligand, HER2 is the preferred heterodimerization partner within the family and can form heterodimers with HER1 and HER3, leading to phosphorylation of tyrosine residues within the cytoplasmic domain [3, 4]. Under certain circumstances, HER2 interacts with its binding partners, including MUC4, HSP90 or gp96, which may stabilize HER2 and make it endocytosis defective [5-8]. As a consequence HER2 heterodimerization with other HER members

(C) The Author(s). 2018 Open Access This article is distributed under the terms of the Creative Commons Attribution 4.0 International License (http://creativecommons.org/licenses/by/4.0/), which permits unrestricted use, distribution, and 
is resistant to downregulation, and induces a variety of signal transduction pathways, such as the PI3K/AKT, Ras/ MAPK, and JAK/STAT pathways, leading to cell transformation and cancer $[9,10]$.

Due to its central role in aggressive tumor growth and metastases, HER2 serves as an ideal target for monoclonal antibody therapy, including the HER2 signaling inhibitor trastuzumab and pertuzumab, which can effectively treat tumors with HER2 gene amplification in 25\% of patients as monotherapy and $50 \%$ when given with chemotherapy [11]. The application of HER2-targeted therapy dramatically changes the clinical outcome for HER2-positive breast cancer patients, even providing a superior prognosis compared to HER2-negative cases. However, acquired and inherent resistance to anti-HER2 therapy in these patients poses a serious challenge, and a better knowledge of the underlying mechanisms of sensitivity to anti-HER2 therapies is of extreme importance for the development of effective strategies to overcome resistance [12].

HER3 is overexpressed in $10-30 \%$ of breast cancer and is also associated with poor prognosis and worse survival [13]. The most important and well-understood signaling activity of HER3 is its unique and potent ability to activate downstream PI3K and AKT pathway signaling, which subsequently controls many biological processes critical for tumorigenesis, including translation, survival, anti-apoptosis, metabolic regulation, and cell cycle control [14]. In addition, HER3 is frequently co-expressed with HER2 in breast cancer, and high levels of HER2/HER3 dimerization are associated with poor survival prognosis in HER2-overexpressing breast cancer [15]. Of note, inhibition of HER2 or the PI3K-AKT pathway in HER2-overexpressing cells is followed by feedback upregulation of HER3, leading to attenuation of the response to inhibition [16, 17]. In HER2-positive metastatic breast cancer, high HER3 expression is linked to poor survival prognosis after anti-HER2 treatment $[18,19]$. All of these studies indicate that there exists crosstalk and co-operativity between HER2 and HER3 expression, and thus, simultaneously targeting HER2 and HER3 may provide a more efficient therapy for breast cancer.

MicroRNAs (miRNAs) are a large family of small noncoding RNA molecules of approximately $22 \mathrm{nt}$ in length that inhibit target gene expression by affecting mRNA stability or/and translational efficacy [20]. Mature miRNA duplexes are loaded onto the RNA-induced silencing complex (RISC), which contains a member of the RNA binding protein Argonaute family (Ago). They then pair with target sites (miRNA response elements, MREs) within the 3'untranslated regions (3'UTRs) of mRNAs to direct posttranscriptional downregulation [21]. Long noncoding RNAs (lncRNAs), pseudogenes, and even viral RNAs have been demonstrated to function as competitive endogenous RNAs (ceRNAs) that elevate the expression of the corresponding protein-coding genes with shared miRNA binding sites via competing with miRNA binding and derepressing the expression of these genes [22-24]. The relative abundance of ceRNAs vs. corresponding RNAs, levels of common miRNAs, and the number of MREs may all contribute to ceRNA interactions, according to a mathematical mass-action model for ceRNA networks [25]. The mechanism is of particular relevance to HER2-positive breast cancer, where amplification of the HER2 gene leads to an enormous number of HER2 mRNA transcripts [26].

Considering that HER2 gene amplification generates highly redundant mRNAs that harbor multiple miRNA binding sites, we speculate that HER2 mRNA acts as ceRNA and can sequester endogenous miRNAs within HER2 positive breast cancer cells, thus cross-regulating the stability and translational efficiency of other host mRNAs with shared miRNA response elements. In this study, we investigated the role of HER2 mRNA in breast cancer by analyzing potential HER 2 mRNA-regulated miRNAs and the corresponding mRNA profiles. We further explored the impact of the interactions between HER2 and its corresponding mRNA on breast cancer growth and tumorigenesis. Our results provide valuable insights into the functional implications of HER2 mRNAs in anti-HER2 resistance.

\section{Methods \\ Cell line}

Human breast cancer cell lines AU565, BT474, T47D, and MCF7 and the human kidney $293 \mathrm{~T}$ cell line were obtained from Cell Resource Center, IBMS, CAMS/ PUMC, China. Cell lines were passaged for $<6$ months after receipt. Cell lines which were passed for $>6$ months were identified by STR Classification. All cell lines were regularly tested negative for Mycoplasma. BT474.TtzmR and AU565.TtzmR sublines with acquired trastuzumab resistance were generated by continuous exposure of parental cells to increasing doses of trastuzumab (up to $10 \mu \mathrm{g} / \mathrm{ml}$ ) for more than 6 months.

\section{sgRNA-CRISPR/Cas9 system design and construction}

Potential target sites were predicted using "crispr.mit.edu" in the human genome, and two to three target sequences with low predicted scores for off-targets were chosen. Two complementary 20-bp oligonucleotides were annealed and cloned this into BbsI-digested pSpCas9(BB)-2A-Puro (PX459). Then, cells were transfected with CRISPR/Cas9 sgRNA. Transfected cells were treated with puromycin at a concentration of $1 \mu \mathrm{g} / \mathrm{ml}$. Surviving cells were sorted into 96-well plates by FACS. The genomic 
region encompassing the CRISPR/Cas9 target site was amplified and sequenced.

\section{Antibodies and reagents}

Trastuzumab (Herceptin) was purchased from a pharmacy. PE-anti-HER2, APC-anti-HER3 antibody was from BioLegend (San Diego, California). Ago2-antibody was purchased from Abcam. All other antibodies were purchased from Cell Signaling Technology. The chemically synthesized specific siRNA, miRNA mimics, miRNA inhibitors, and non-specific control, as well as cholesterol-conjugated siRNA and miRNA mimics and control mimics, were purchased from RiboBio Co., Ltd. (Guangzhou, China).

\section{Real-time PCR}

Total RNA was extracted with Trizol Reagent and quantified by real-time PCR using the SYBR Green Premix Reagent (Takara Bio Inc., Shiga, Japan) with an internal control for normalization.

\section{TaqMan miRNA analysis}

Real-time PCR analysis for miR-125a/b was performed using a TaqMan miRNA Kit (Applied Biosystems). The U6 endogenous control was used for normalization. Relative expression was quantified using the comparative threshold cycle $(\mathrm{Ct})$ method.

\section{Luciferase assay}

To validate miRNA targeting, the 3'UTRs of HER2 and HER3 were cloned into the pGL3 firefly luciferase reporter plasmid. Cells were transfected in 48-well plates with $20 \mathrm{ng}$ of pGL3 reporter, $2 \mathrm{ng}$ of pRL-TK as the control, and $100 \mathrm{nM}$ miRNA mimic. Firefly luciferase and Renilla luciferase activities were measured consecutively with the dual luciferase reporter system (Promega), and the firefly luciferase activity was normalized to that of Renilla luciferase after $48 \mathrm{~h}$. To test the ceRNA activity of the HER2 3'UTR, $5 \times 10^{4} 293 \mathrm{~T}$ cells were transfected in 48-well plates with $20 \mathrm{ng}$ of pGL3-HER3 3'UTR and $250 \mathrm{ng}$ of pCDNA3.1-HER2 3'UTR or pCDNA3.1 as a control, as well as $1-10 \mathrm{nM}$ miRNA mimic. Firefly luciferase and Renilla luciferase activities were measured consecutively with the dual luciferase reporter system (Promega), and the firefly luciferase activity was normalized to that of Renilla luciferase after $48 \mathrm{~h}$.

\section{Transcriptional profiling by microarray}

Comparative microarray analysis of mRNAs from T47D cells transfected with pCDNA3.1-HER2 3'UTR and pCDNA3.1 as a control was performed on an Agilent Whole Human Genome Microarray at the Shanghai Biotechnology Corporation according to manufacturer's instructions.

\section{RNA immunoprecipitation}

Cells were washed and lysed. Ago2-antibody or control IgG was incubated with ProteinG Sepharose beads (GE Healthcare). The beads were pelleted and washed and then subsequently incubated with cell lysate. After incubation, the beads were washed. RNA was isolated from the immunoprecipitated pellet by adding Trizol reagent. Total RNA was used for reverse transcription and real-time PCR analysis. The following primers were used: Ago-HER2 forward, 5'-AGCCGCGAGCACCC AAGT-3' and reverse, 5'-TTGGTG GGCAGGTAG GTGAGTT'; and Ago-HER3 forward, 5'-GGGTTAGAG GAAGAGGATGTCAAC-3' and reverse, 5' - GGGA GGAGGGAGTACCTTTGAG'.

\section{Transcript copy-number analysis}

RNA was extracted from $1 \times 10^{5}$ cells using Trizol Reagent. Absolute quantification of total HER2 and HER3 mRNAs and miR-125a/b was performed by real-time PCR. For a standardized evaluation, threshold cycle (CT) values were compared to a 10 -fold serial dilution of either in vitro-transcribed HER2 or HER3 mRNAs or synthetic miR-125a/b mimics (RiboBio Co., Ltd). Then, the copies of transcript per cell were calculated with standard stoichiometric methods.

\section{Animal studies}

Tumors were established by orthotopic injection of $1 \times$ $10^{7}$ cells/mouse in $200 \mu \mathrm{l}$ of PBS into the flanks of six-week-old female nude mice. The mice were randomly divided into groups at $15 \mathrm{~d}$ after inoculation. Tumor growth was measured every 3 days. Trastuzumab $(10 \mathrm{mg} / \mathrm{kg}$ ) was given intraperitoneally (i.p.) once a week. For delivery of cholesterol-conjugated siRNA, $10 \mathrm{nM}$ siRNA in $0.1 \mathrm{ml}$ PBS was locally injected into the tumor mass every 3 days for 2 weeks. Tumor growth was measured twice weekly, and the volume of the tumors was calculated as volume $=$ length $\times$ width $^{2} / 2$.

\section{Immunohistochemistry analysis}

Tissues were fixed in $4 \%$ paraformaldehyde overnight and embedded in paraffin according to standard procedures. Tissue sections were stained with the following procedures. Briefly, after deparaffinization and rehydration, antigen retrieval was performed using antigen retrieval butter in an autoclave at $121{ }^{\circ} \mathrm{C}$ for $100 \mathrm{~s}$. Slides were then incubated with primary antibodies at room temperature for $40 \mathrm{~min}$. Slides were washed with PBS and stained with fluorescence-conjugated secondary antibodies. Images were acquired using a Leica TCS SP8 confocal laser-scanning microscope (Leica Microsystems, Heidelberg, Germany). 


\section{Breast primary tumor cells isolation and transfection} Informed written consents were obtained from breast cancer patients according to the General Hospital of People's Liberation Army. Tumor biopsy was washed with PBS containing $100 \mathrm{U} / \mathrm{ml}$ penicillin and $100 \mu \mathrm{g} / \mathrm{ml}$ streptomycin, and was cut up into small pieces. Small tissues were minced in RPMI1640 medium. To obtain single cell suspensions, samples were treated with $1 \mathrm{mg} /$ $\mathrm{ml}$ collagenase type IV and $1 \mathrm{mg} / \mathrm{ml}$ hyaluronidase followed by digestion with trypsin-EDTA at $37{ }^{\circ} \mathrm{C}$ for about $4 \mathrm{~h}$ with periodic agitation. After digestion, cells were centrifuged and cultured in RPMI1640. Fibroblast like elongated cells were visible firstly. Later, epithelial like cells started to make colonies in dome like shapes. These cell colonies were isolated and transferred to cell plates. These cells were passaged and expanded for transfection experiments.

Transfections were carried out using electroporation with Bio-rad transfection system according to the manufacturer's instructions. Briefly, $1 \times 10^{6}$ cells were transfected with $10 \mu \mathrm{g}$ plasmids using a BioRad Gene Pulser II at $250 \mathrm{~V}$ and $950 \mu \mathrm{F}$. Each treatment was performed for at least three times.

\section{Expression data from the cancer genome atlas}

The transcriptome expression profiles of breast cancer were downloaded from The Cancer Genome Atlas (TCGA) data portal (https://cancergenome.nih.gov). In this study, the transcriptome profiles of 887 cases and 101 HER2-positive breast tumors were included in the coexpression analysis. Level 3 Illumina miRNASeq was used to analyze miRNA expression. For the miRNASeq data, "reads_per_million_miRNA_mapped" values were used to calculate miRNAs.

\section{Statistical analyses}

Data are expressed as the mean \pm SD (standard deviation) from three independent experiments. The statistical significance between two and more than two groups was measured using the two-tailed Student's t-test. $P$ values $<0.05$ were considered significant.

\section{Results}

\section{The HER2 3'UTR enhances breast cancer cell malignancy}

We first tested the effects of ectopic expression of the HER2 3'UTR in human breast cancer cells. Similar to cells transfected with the HER2 coding sequence (CDS), cells transfected with the HER2 3'UTR displayed increased cell proliferation compared to control vector-transfected cells (Fig. 1a). In addition, HER2 3'UTR-transfected cells formed more colonies than control cells (Fig. 1b). We further tested the tumor growth promoting ability of the HER2 3'UTR in vivo. As shown in Figs. 1c-e, HER2 3'UTR-transfected cells developed larger tumors compared to control cells (all $P<0.05$ or 0.01 ). Tumor sections were stained for Ki67, a marker of cell proliferation. As shown in Fig. 1f, HER2 3'UTR-transfected tumors displayed a significantly higher level of Ki67-positive cells than that of the control cells.

\section{The HER2 3'UTR modulates HER3 expression}

To explore HER2 3'UTR-dependent transcriptional programs, we analyzed gene-expression profiles of T47D cells transfected with the HER2 3'UTR. Compared to control cells, HER2 3'UTR-transfected cells showed upregulation of 4670 probes and downregulation of 4341 probes (Additional file 1: Table S1, $\log _{2}$ (fold change) $>0.5$ ). To define key pathways regulated by the HER2 3'UTR, gene-set enrichment analysis was performed. Among the top 50 enriched pathways, the Jak-STAT and ErbB signaling pathway were affected by the HER2 3'UTR (Additional file 2: Table S2). As the ErbB family plays a key role in tumor growth and development in breast cancer, we focused on the ErbB pathway in this study. As shown by microarray heat mapping, HER2 (ErbB2), HER3 (ErbB3), HER4 (ErbB4), NRG2, and NRG3 were up-regulated by expression of the HER2 3'UTR (Fig. 2a). The microarray results were further confirmed by real-time PCR analysis (Fig. 2b).

HER3 was selected for further study as the HER2HER3 heterodimer constitutes the most mitogenic receptor complex and the key oncogenic unit within the HER family [14]. As represented in Fig. 2c and d, a significant increase of HER3 mRNA and protein levels was observed in HER2 3'UTR-transfected cells. Similar results were observed in primary breast cancer cells (Fig. 2e). Cell surface HER3 levels were elevated by 1.6-fold and 1.5-fold for T47D and MCF7, respectively, as detected by flow cytometry (Fig. 2f). Furthermore, increased HER3 protein levels were observed in xenograft tumors stably transfected with the HER2 3'UTR, as detected by immunostaining (Fig. 2g). The HER2 3'UTR enhanced activation of AKT and PI3K signaling downstream of HER2/HER3 heterodimers (Fig. 2h). We further compared the effects of the HER2 3'UTR and HER2 CDS on HER2/HER3 expression. As can be seen in Fig. 2i, both the HER2 3'UTR and CDS increased HER2 and HER3 protein levels. However, only the HER2 3'UTR elevated HER3 mRNA levels (Fig. 2j), indicating that the HER2 3'UTR-induced increase in HER3 protein levels may be due to its elevated mRNA levels. HER2 CDS increased HER3 protein levels likely by forming heterodimers and reducing HER3 endocytosis and subsequent degradation [27]. In contrast, no obvious change in EGFR levels was observed by the HER2 3'UTR (Fig. 2k). The HER-2 3'UTR also elevated HER4 protein levels possibly through ceRNA crosstalk as the HER2 and HER4 3'UTRs have shared miRNA binding sites 


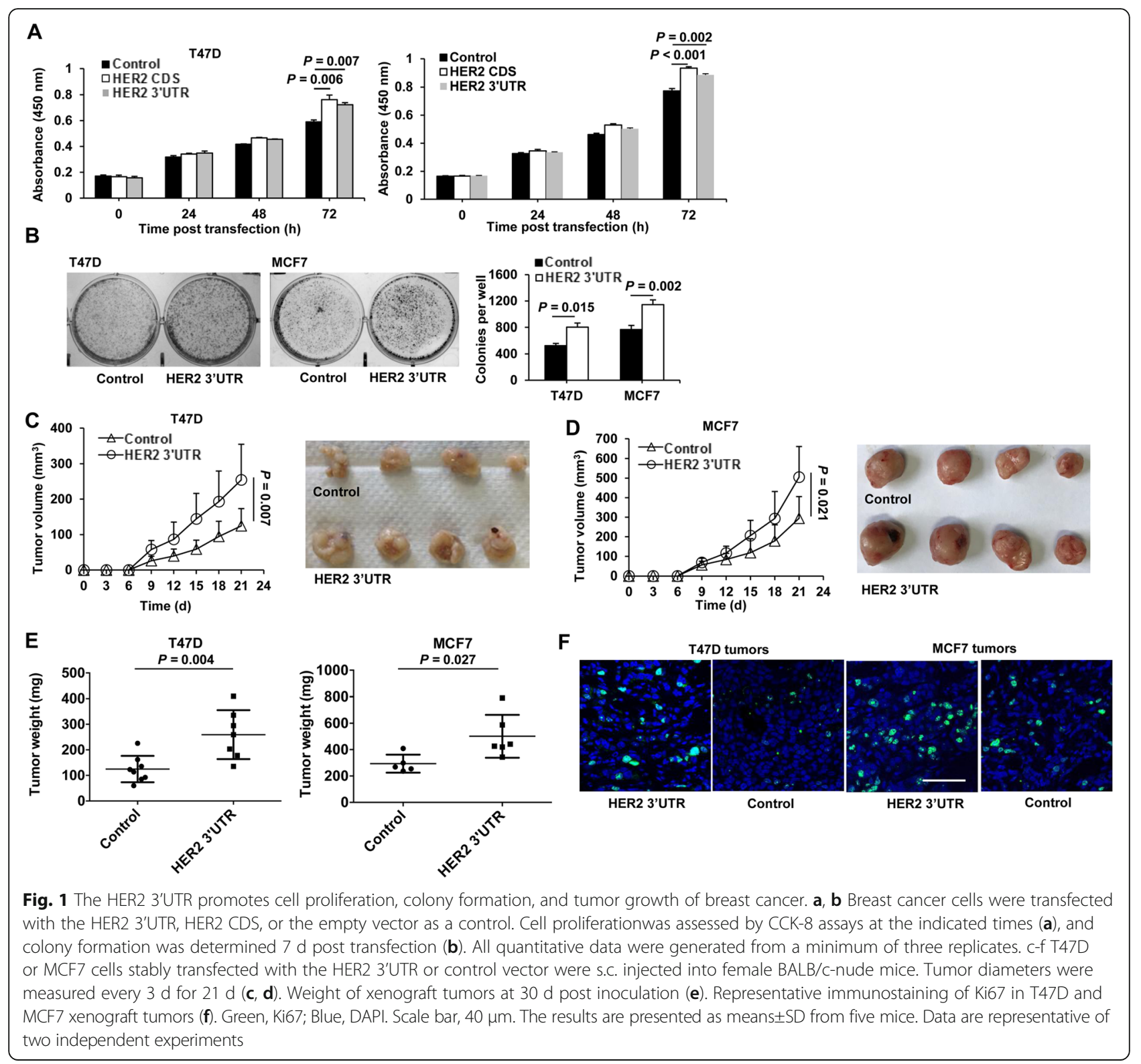

(Additional file 3: Table S3). Altogether, these data suggested that there is cross-talk between HER3 mRNA and the HER2 3'UTR.

The HER2 3'UTR promotes cell malignancy in a miR-125a/ b response element-dependent manner

As shown in Fig. 3a, the HER2 3'UTR elevated the activity of a HER3 3'UTR luciferase reporter. In addition, HER3 mRNA was recruited to RISCs at much lower levels in HER2 3'UTR-transfected cells compared to control cells (Fig. 3b). MiRNA prediction indicated that 61 miRNAs have binding sites in both human HER2 and HER3 3'UTRs (Additional file 4: Table S4), among which miR-125-5p, miR-27a-5p, and miR-378 ranked in the top
100 in miRNA abundance in breast invasive carcinoma (TCGA). We then tested if these shared miRNAs are involved in regulation of HER3 expression via the HER2 3'UTR. miR-125a and miR-125b, which target the HER2 3'UTR at nucleotides $17-44$ and 19-44, respectively [28, 29], significantly repressed HER2 and HER3 3'UTR luciferase reporters (Fig. 3c). Transfection of moderate amounts of miR-125a or miR-125b endowed the HER2 3'UTR with the capacity to regulate HER3 expression in miR-125a/b low expressing $293 \mathrm{~T}$ cells (Fig. 3d). No effect on HER3 luciferase reporter by HER2 3'UTR was observed in $293 \mathrm{~T}$ cells that were not transfected with $\mathrm{miR}-125 \mathrm{a} / \mathrm{b}$. This is due to low expression of $\mathrm{miR}-125 \mathrm{a} / \mathrm{b}$ in $293 \mathrm{~T}$ cells, and a 


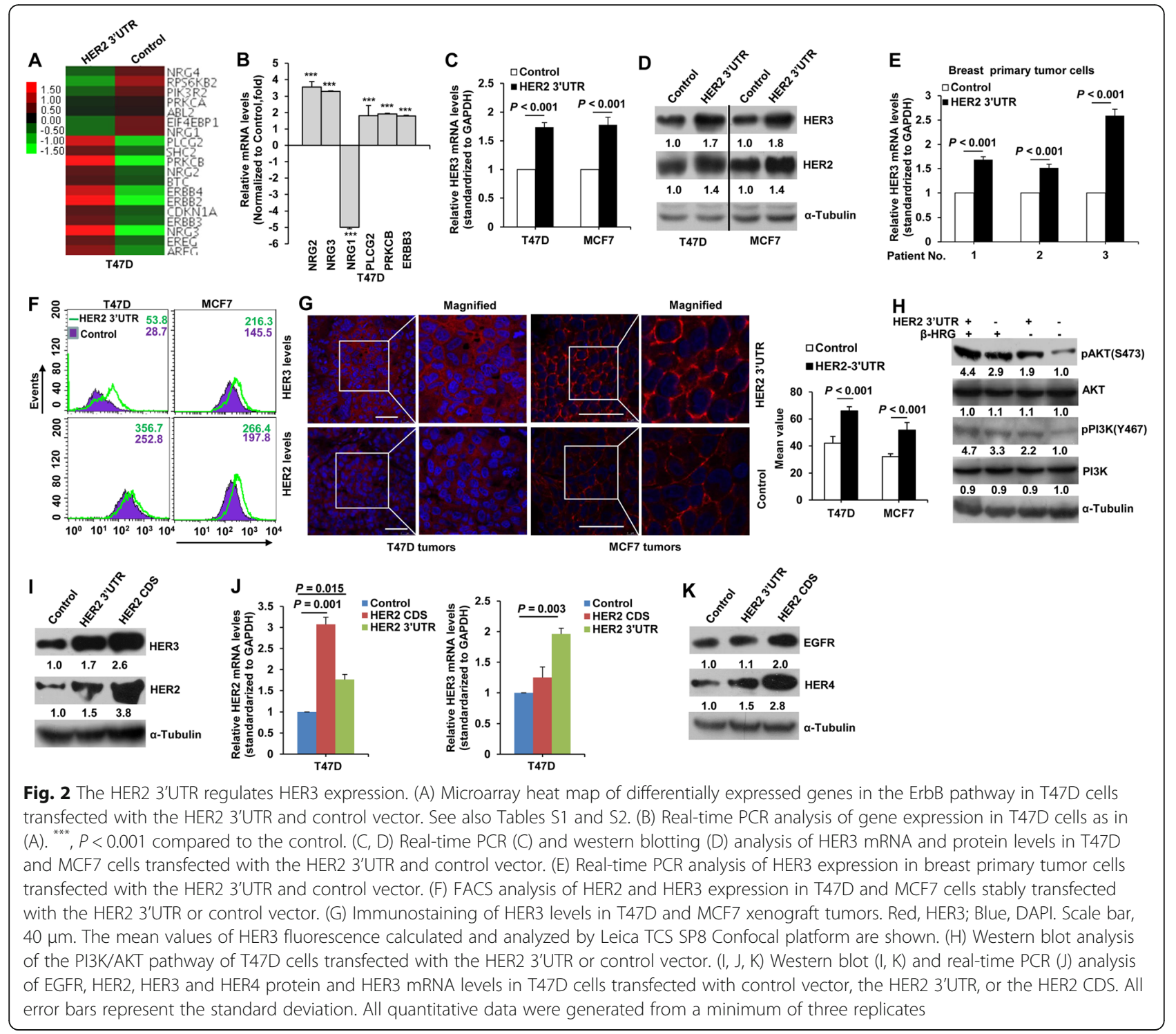

minimum amount of miR-125a/b is required for regulation of HER3 expression by HER2 3'UTR. In contrast, depletion of miR-125a and miR-125b with inhibitors blocked HER2 3'UTR-mediated elevation of HER3 expression in miR-125a/b-rich T47D cells (Fig. 3e).

To investigate the effect of miR-125a/b response elements on HER3 expression, mutations were introduced into the HER2 3'UTR within the miR-125a/b binding sites as shown in Fig. 3f. Up-regulation of the luciferase activity of the HER3 3'UTR (Fig. 3g), HER3 mRNA (Fig. $3 \mathrm{~h}$ ), and protein (Fig. 3I) levels was significantly attenuated by the mutated HER2 3'UTR, compared to wild type HER2 3'UTR. In addition, mutated HER2 3'UTR also significantly attenuated the ability to enhance cell proliferation (Fig. 3j) and colony formation (Fig. 3k).
Finally, the effect of the HER2 3'UTR on cell proliferation was largely abolished by miR-125a and miR-125b depletion (Fig. 3l). Taken together, these results demonstrate that the miR-125a/b response element is essential for HER2 3'UTR regulation of HER3 and cell malignancy.

\section{Both the CDS and 3'UTR contribute to HER2 oncogenic potential}

We dissected the roles of the HER2 CDS and 3'UTR on HER2-mediated tumor growth. We constructed HER2 CDS, 3'UTR, and full-length HER2 (including both the CDS and 3'UTR) expression vector (Fig. 4a). The HER2 3'UTR and full-length HER2, but not the HER2 CDS, elicited a significant increase in HER3 mRNA levels (Fig. 4b), whereas all of the constructs increased HER3 


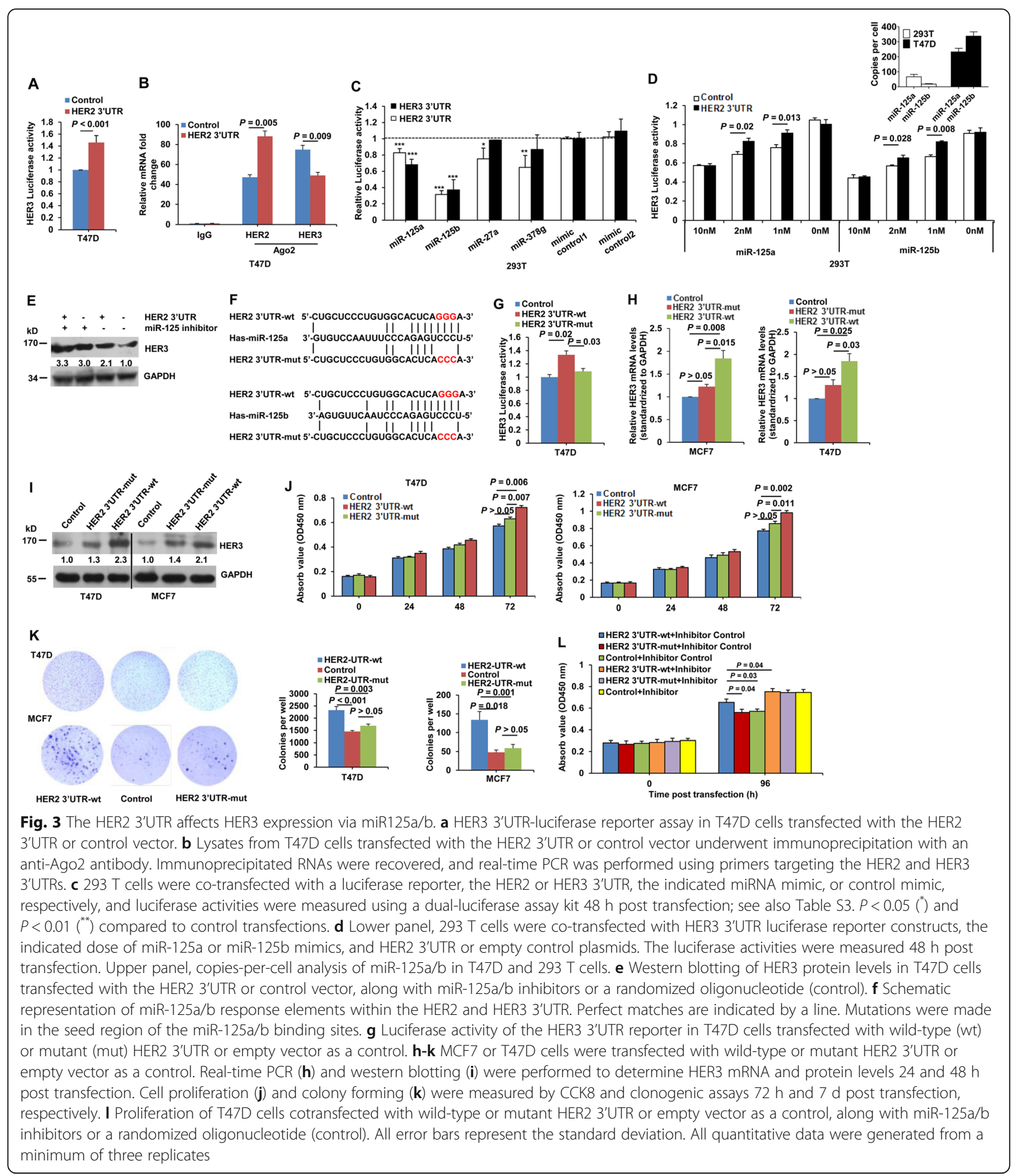

protein levels, with full-length HER2 yielding the largest increase (Fig. 4c). Accordingly, transfection of the HER2 3'UTR, CDS, or the full-length construct all significantly increased cell growth and colony formation (Fig. $4 \mathrm{~d}$ and e). Moreover, cells stably transfected with the HER2 3'UTR and CDS developed larger tumors compared to controls (Fig. 4f). Full-length HER2 led to the largest increase in cell proliferation, colony formation, and tumor growth. Increased HER3 expression was also observed in HER2 3'UTR-, CDS-, or full-length-overexpressing tumors (Fig. 4g). We further mutated the start codon of the HER2 CDS to prevent HER2 protein 


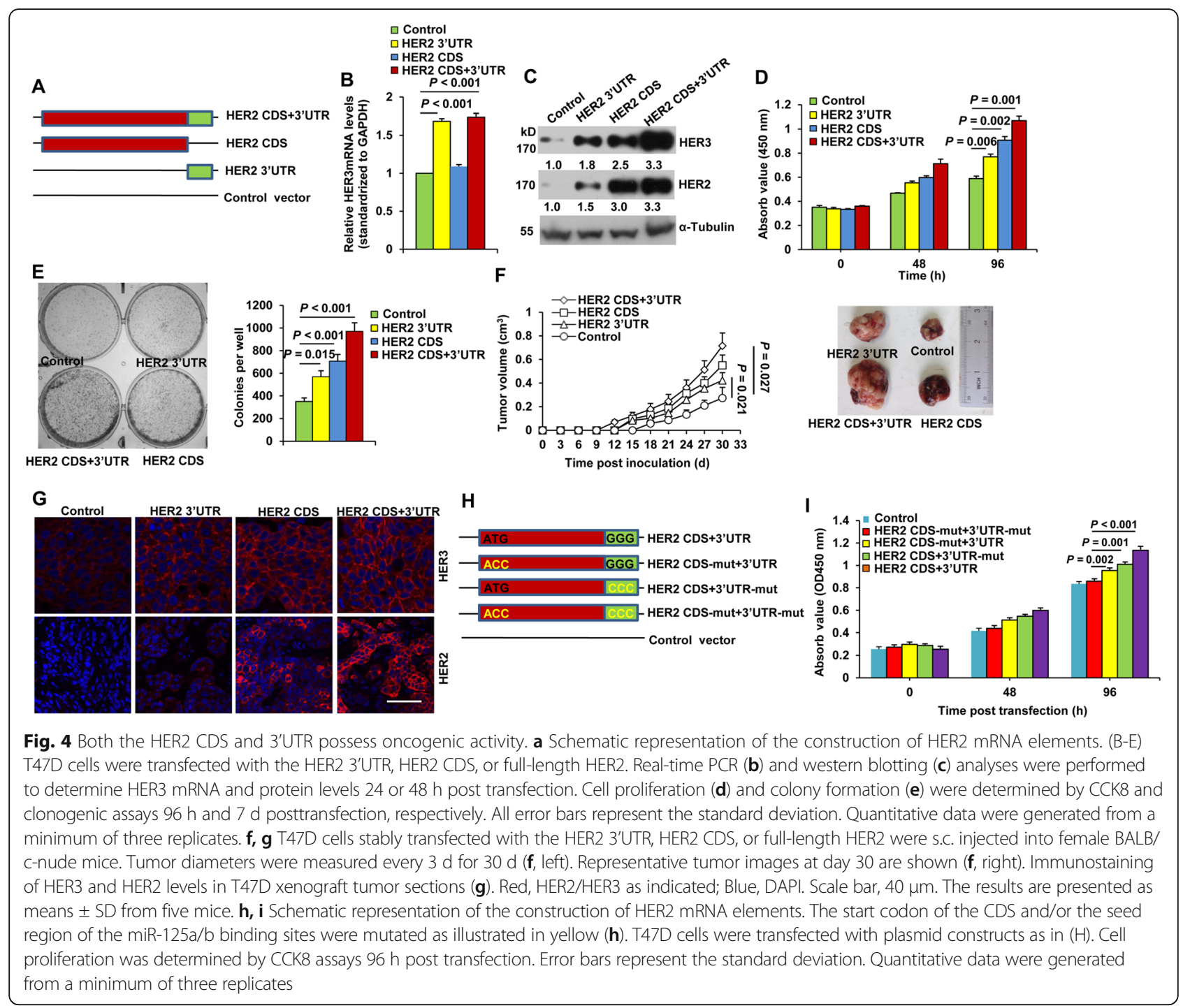

expression (Fig. 4h). As seen in Fig. 4i, transfection of this HER2 construct that ablates protein expression but preserves 3'UTR mRNA expression still stimulated cell proliferation.

\section{HER2 3'UTR-induced HER3 upregulation confers trastuzumab resistance}

An important consideration in the HER2 mRNA-miR125a/b-HER3 mRNA interaction is their absolute levels in cells, so we measured the copy numbers of their transcripts by real-time PCR calibrated with an internal standard curve of a HER2 or HER3 expression vector or synthetic miR-125a/b mimics. As shown in Fig. 5a, there were $~ 10,000-20,000$ HER2 mRNA transcripts per cell in HER2 over-expressing cells. miR-125a/b was expressed at $\sim 100-200$ molecules per cell. In contrast, HER3 mRNA was expressed at only $\sim 30$ molecules per cell. A low ratio of miR-125a/b:HER2 mRNAs and high ratios of miR-125a/b:HER3 and HER2:HER3 mRNAs were found in HER2 over-expressing cells, which further indicates that the interaction between HER2 and HER3 mRNAs occurs under such a circumstance. Of note, trastuzumab treatment led to upregulation of HER2 and HER3 mRNA levels in both dose-dependent and time-dependent manners (Fig. 5b-c). Trastuzumab had no obvious effect on miR-125a expression levels and only slightly decreased miR-125b levels (Additional file 5: Figure S1). Only a moderate decrease in HER3 protein levels was observed by transient treatment with trastuzumab (Additional file 6: Figure S2), which may be because the amount of increased HER3 by HER2 mRNAs could not totally compensate for the loss of HER3 by decreased HER2 protein. The enhancement of trastuzumab on HER3 mRNA expression was largely abrogated in cells treated with miR-125a and miR-125b inhibitors (Fig. 5d), validating that 


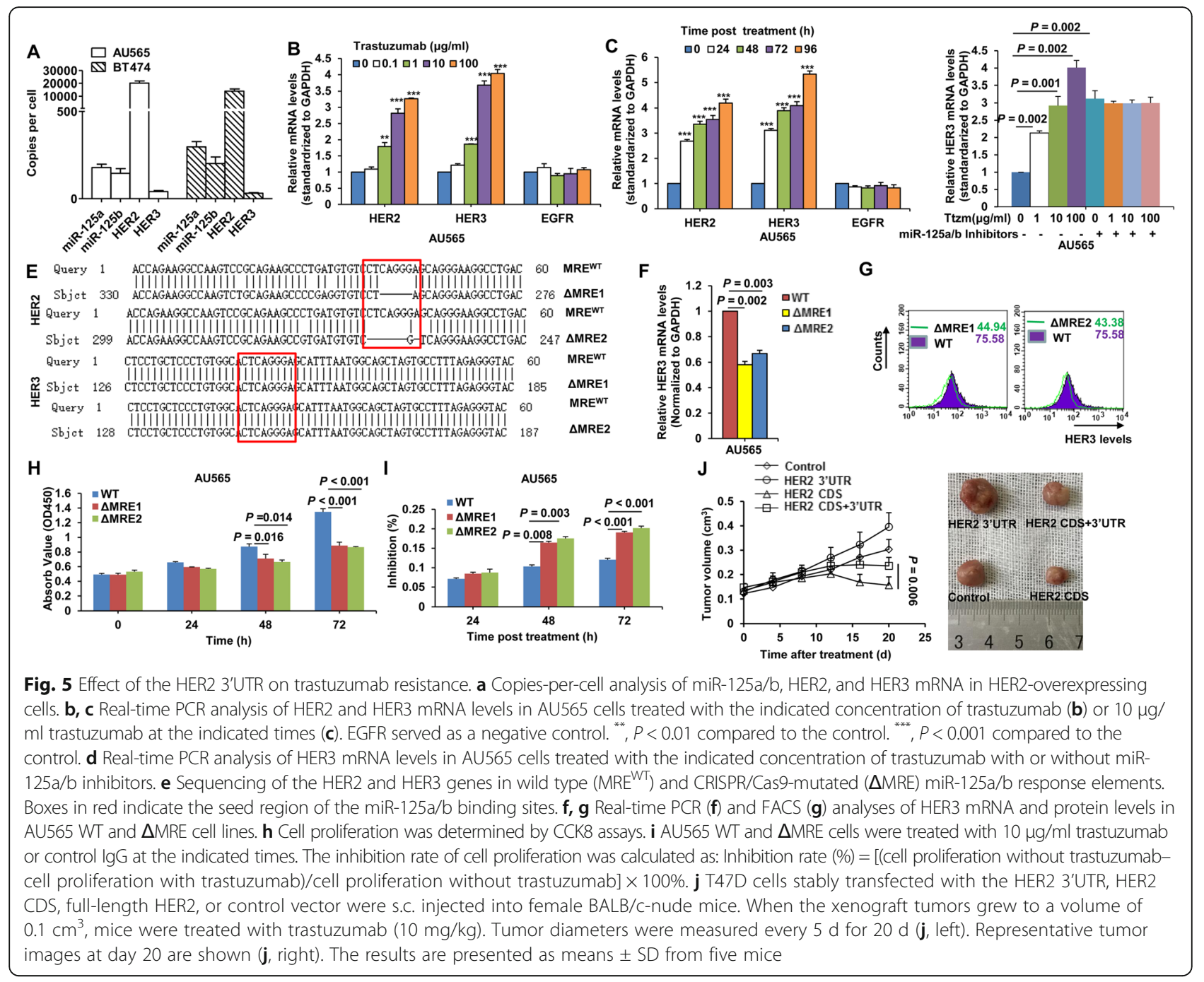

upregulation of HER3 mRNA by trastuzumab was dependent on $\mathrm{miR} 125 \mathrm{a} / \mathrm{b}$.

AU565 cells were then treated with increasing doses of trastuzumab for more than 6 months to obtain a trastuzumab-resistant clone, TtzmR. Both HER2 and HER3 mRNA levels were increased in TtzmR cells compared to parental cells (Additional file 7: Figure S3A). In addition, a substantial downregulation of HER2 protein levels and an obvious upregulation of HER3 were observed in the trastuzumab-resistant cells (Additional file 7: Figure S3B, S3C). We then investigated whether combinatory treatment with HER3 siRNA and trastuzumab could be a useful strategy for overcoming trastuzumab resistance. As shown in Figures (Additional file 7: Figure S3D and S3E, knocking down HER3 significantly restored the sensitivity of the trastuzumab-resistant cells to trastuzumab treatment, both in vitro and in vivo. The efficiency of HER3 knock down by RNAi was determined by IF staining (Additional file 7: Figure S3F). To further determine the role of the HER2 3'UTR on trastuzumab resistance, we generated a mutant AU565 cell line lacking the seed sequence within the miR-125a/ b responsive element ( $\triangle \mathrm{MRE}$ ) by CRISPR/Cas9. Two clones were selected after sequencing (Fig. 5e). Compared to wild type cells, $\triangle \mathrm{MRE}$ cells displayed decreased levels of HER3 mRNA (Fig. 5f) and protein (Fig. 5g), as well as decreased cell proliferation (Fig. 5h). In addition, greater inhibition by trastuzumab was observed in mutant cells (Fig. 5i). Finally, cells stably expressing the HER2 3'UTR displayed increased tumor resistance to trastuzumab treatment (Fig. 5j). Together, these data indicate that the HER2 3'UTR is involved in trastuzumab resistance in breast cancer.

\section{Correlation between HER2 and HER3 levels in primary breast cancer}

We further assessed HER2 and HER3 mRNA levels in breast cancer patients. Quantitative real-time PCR analysis revealed a significant positive correlation between HER2 and HER3 mRNA levels in 80 breast cancer 


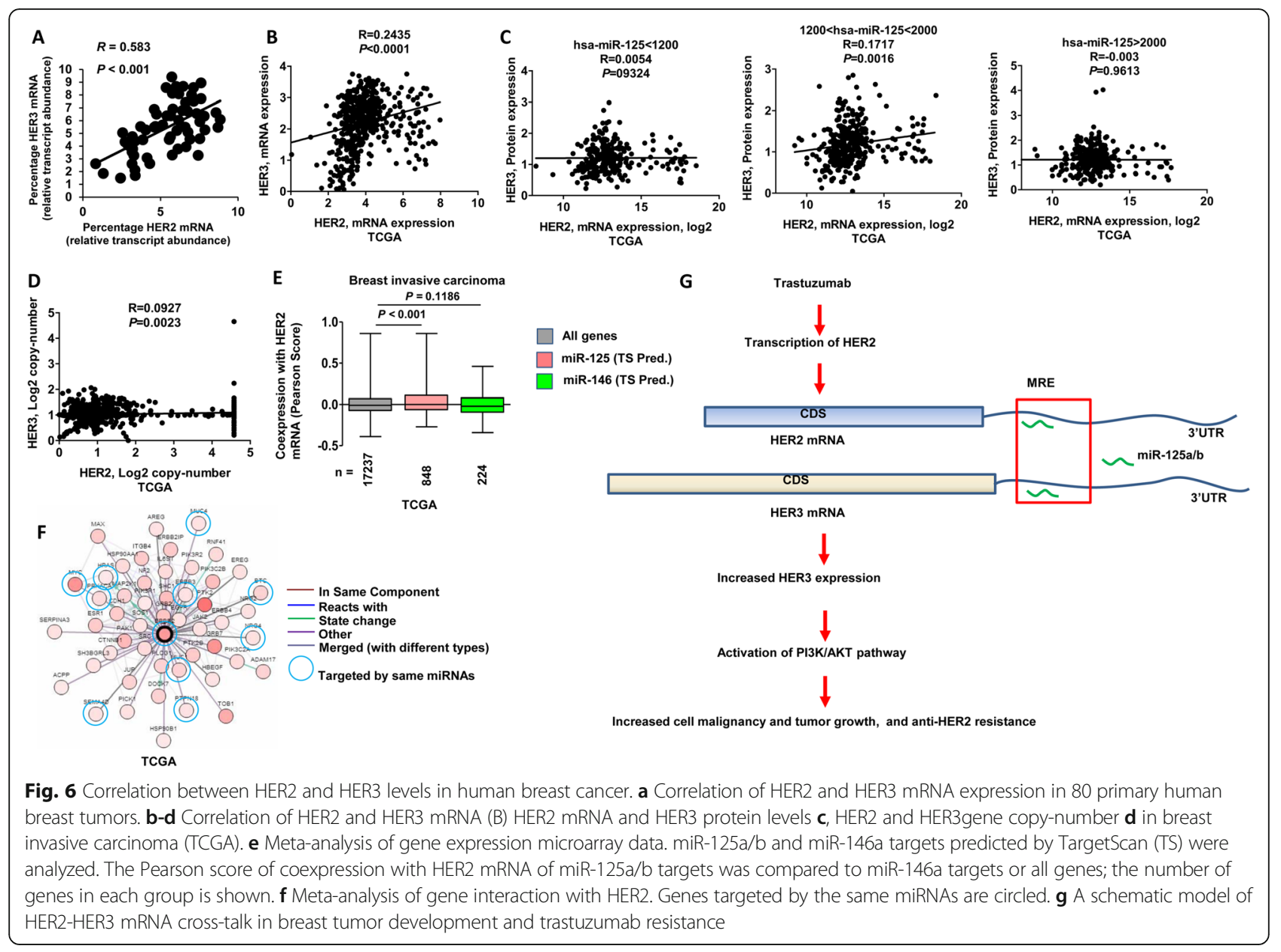

tumors (Fig. 6a). Sequencing of the HER2 3'UTR showed that there was strict sequence conservation among tumors (data not shown). We next interrogated The Cancer Genome Atlas's data for HER2 and HER3 expression. As shown in Fig. 6b, there is a significant correlation between HER2 and HER3 mRNA levels in breast cancer. Importantly, a positive correlation between HER2 mRNA and HER3 protein levels was observed in patients with medium amounts of miR-125a/b (Fig. 6c), which is consistent with the observation in cell experiments (Fig. 3d). However, no such correlation was seen between HER2 and HER3 gene copy numbers (Fig. $6 \mathrm{~d})$. There is no correlation between miR-125a/b and protein levels of HER1 and HER2 in HER2 positive patients (Additional file 8: Figure S4), which may be due to a high ratio of HER2 mRNAs:miR-125a/b. In addition, no correlation between miR-125a and HER3 protein and only a weak correlation between miR-125b and HER3 protein level were observed, indicating that highly abundant HER2 mRNAs may sequester most miR-125a/b. Taken together, these data suggest that HER2 mRNA upregulates HER3 expression through miR-125a/b in primary breast cancer. We further performed a meta- analysis using TCGA data. By comparing expression levels of predicted miR-125a/b targets to those of all genes in the microarray data, we found a significant elevation in predicted miR-125a/b targets compared to all genes or to non-miR-125a/b targets (Fig. 6e). Aside from HER3, HER2 mRNA may act as a sponge to absorb other shared miRNAs and up-regulate the corresponding oncogenes, such as MYC, mucin 1/4 (MUC1 and MUC4), semaphorin 4D (Sema4D), and HRAS (Fig. 6f).

\section{Discussion}

HER2 heterodimerization with other HER members leads to the most potent of receptor combinations for causing continual downstream PI3K/Akt, Ras/MAPK, and JAK/STAT signaling, which drives oncogenic transformation and breast tumor growth. In the present study, we investigated whether highly expressed HER2 mRNAs in HER2 gene-amplified breast cancer could directly affect the expression of other HER members via shared MREs. We focused on HER3 because, as a specialized allosteric activator, it has a unique and potent ability to activate the downstream PI3K and AKT pathways. We showed herein that the HER2 3'UTR 
derepresses HER3 by sequestering cellular miR-125a/b in breast cancer cells and tumors. The tumor growth promotion effect of the HER2 3'UTR was nearly comparable to the HER2 CDS (Fig. 4). Our study establishes the HER2 3'UTR as a potent oncogenic transcript that elevates the expression of HER3 and activates downstream AKT and PI3K pathways in a MRE-dependent and coding-independent manner. These results are consistent with the observation of the positive correlation between HER2 and HER3 mRNA levels in breast cancer patients. Remarkably, we demonstrated that inhibition of HER2 with trastuzumab results in time- and dose-dependent upregulation of HER3 mRNA and protein by the HER2 3'UTR, which confers trastuzumab resistance. Our results may therefore provide further dissection of the impact of HER2 overexpression on both HER3 mRNA regulation and anti-HER2 resistance, as shown in Fig. 6g. In this model, HER2 mRNA-mediated HER3 up-regulation plays an important role in breast cell transformation, tumor growth, and resistance to anti-HER2 therapy. These data imply that targeting HER2/HER3 mRNAs may provide an effective strategy for the treatment of HER2-positive breast cancer.

In HER2-amplified cancer, activation of HER3 may occur through high-level expression of heterodimerization with HER2 [30]. HER3 is classified as a pseudokinase which lacks intrinsic kinase activity. HER2 has no known ligands but can dimerize with other HER family members, especially HER3. HER3 can be phosphorylated and activated by residual HER2 activity. Phosphorylated HER3 in turn activates PI3K via its six docking sites for the $\mathrm{p} 85$ adaptor subunit of PI3K. Due to HER3-mediated compensation, current clinical therapy against HER2 will not block PI3K pathway completely, resulting in unrestrained PI3K-AKT-mTOR signaling that is essential for tumorigenesis and drug resistance [14, 31, 32]. In breast carcinoma, HER3 levels can significantly increase due to overexpression instigated via gene amplification [33], transcription, and protein translation $[15,17,34]$ or via enhanced molecular stability by dimerization [27]. miRNAs affect HER3 expression at the post-transcription level [29, 35-38]. Both HER2 and HER3 are validated targets of miR-125a and miR-125b [28].

HER2/HER3 co-overexpression is significantly associated with metastasis and shorter survival in breast cancer $[13,39]$. All of these studies indicate that there may be crosstalk and cooperativity between HER2 and HER3. Our current work suggests that besides by HER2 protein heterodimerization, HER2 overexpression in breast cancer up-regulates HER3 via the HER2 3'UTR, which acts as a sponge to bind and sequester endogenous miR-125a/b. The HER2 3'UTR increases HER3 mRNA levels in a miR-125a/ b response element- and miR-125a/b-dependent manner. HER2 3'UTR-induced miR-125a/b sequestration results in reduced Ago2 binding and HER3 mRNA derepression. In addition, a low ratio of miR-125a/b: HER2mRNAs and high ratios of miR-125a/b: HER3 mRNA and HER2:HER3 mRNAs were displayed in HER2 gene-amplified and protein-overexpressing breast cancer cells (Fig. 5a), which further indicates that the interaction between HER2 and HER3 mRNA may occur under such a circumstance. We consider that HER2 3'UTR preferentially regulates HER3 mRNA level but not vice versa, as the binding affinity between HER2 3'UTR and miR-125a/b was relatively higher than that between HER3 3'UTR and miR-125a/b by the maximum free energy predicted hybridization configurations (data not shown) and luciferase reporter assay (Fig. 3a and Additional file 9: Figure S5), and a high ratio of HER2:HER3 mRNAs were found in HER2 gene amplified cells (Fig. 5a). Besides HER3, expression levels of HER4 in HER2 3'UTR-transfected cells were also increased (Fig. 2a, k). MiRNA prediction indicated that 46 miRNAs have binding sites in both human HER2 and HER4 3'UTRs (Additional file 3: Table S3). These data suggested that HER2 may also regulate HER4 expression through ceRNA crosstalk.

Trastuzumab and pertuzumab, monoclonal antibodies targeting HER2 homodimerization and heterodimerization, as well as the HER2 tyrosine kinase inhibitor (TKI), display considerable clinical efficiency. However, the high prevalence of drug resistance after continuous treatment is a major concern [40, 41]. Several lines of evidence demonstrate that upregulation of HER3 is one of the main roads to resistance to anti-HER2 therapies [42, 43]. In current study we found that trastuzumab treatment upregulated HER3 expression via elevated HER2 3'UTR. Although anti-HER2 therapies lead to substantially decreased HER2 level, upregulated HER3 may form dimmers with other kinase including EGFR, FGFR, Met, Src that could also phosphorylate and activate HER3 [16, 44-46]. In addition, even the maximal doses of trastuzumab did not totally deplete HER2 expression (see Additional file 10: Figure S6), it is possible that the residual HER2 kinase activity was enough to partly maintain HER3 phosphorylation. All these could lead to resistance to HER2-targeted therapies. Breast cancer patients with high levels of HER2/HER3 dimerization have poor survival prognosis under treatment with adjuvant trastuzumab [15]. Moreover, a phase II clinical trial study shows that that low HER3 mRNA may represent a pertuzumab-sensitive phenotype in an enriched ovarian cancer patient [47]. Besides, elevated expression of HER3 and MUC4 and their interactions that possibly induced by increased phosphorylation of ERK and expression of PI3K and c-Myc were observed in HER2 knockdown pancreatic cancer cells, leading to increased cell proliferation, motility and tumorigenicity [48]. The feedback mechanisms of inhibition of HER2 or the PI3K/AKT pathway lead to a rebound in HER3 expression and signaling, which provides a rationale for the combination of targeted-therapies and 
drugs targeting HER2 and HER3. Indeed, dual targeting of HER2 and HER2/HER3 dimerization with trastuzumab and pertuzumab results in enhanced tumor inhibitory effects in mouse xenograft models, and significantly prolongs progression-free survival in HER2-overexpressing breast cancer $[11,49,50]$.

Consistent with these previous studies, our findings show that continuous treatment with trastuzumab leads to a substantial down-regulation of HER2 protein levels but a compensatory upregulation of HER2 mRNA, thereby leading to increased HER3 mRNA levels through ceRNA crosstalk. Trastuzumab upregulated HER3 in a miR125a/b-dependent manner as elevated HER2 mRNA by trastuzumab treatment sequestered endogenous miR-125a/b by its 3'UTR and subsequently derepressed HER3 mRNA. Targeting of HER3 with siRNA and/or mutation of the miR-125a/b responsive element within the HER2 3'UTR sensitized HER2-overexpressing breast cancer cells and xenografts to trastuzumab. Our study therefore presents an effort to address the mechanism of regulation of HER3 mediated under anti-HER2 treatment, which further supports the notion that inhibition of HER3, especially targeting HER2 mRNA might provide a novel therapeutic approach for HER2-targeted therapies in breast cancer.

The sensitivity of breast cancer to trastuzumab is directly related to HER2 expression levels, and elevated HER3 is involved in trastuzumab resistance. Although transfection of HER2 CDS and full-length gene both led to increased HER3 expression, they highly elevated HER2 expression in the meantime (see Fig. 4c and g), transforming T47D cells into HER2-positive cells and therefore making these cells more sensitive to trastuzumab. In contrast, HER2 3'UTR only moderately increased HER2 level. This may explain why cells stably expressing the HER2 3'UTR displayed more resistance to trastuzumab treatment than those expressing HER2 CDS or full-length gene (see Fig. 5j). As trastuzumab-induced upregulation of HER3 mRNA was largely dependent on miR125a/b and the HER2 3'UTR (see Fig. 5), we believe that HER2 3'UTR-mediated HER3 upregulation plays an important role in the increased HER3 expression under trastuzumab treatment. In addition, it is worthwhile to fully dissect the cross-regulatory function of HER2 mRNAs on other pathways and their casual role in breast cancer development and drug resistance.

\section{Conclusion}

Our study demonstrates that HER2 mRNAs posttranscriptionally up-regulate HER3 via the sequestration of miR-125a/b, contributing to enhanced breast cancer growth and acquired anti-HER2 resistance. Given that HER2 amplification in breast cancer usually generates highly redundant transcripts, our study therefore supports the notion that the inhibition of HER2 mRNA and/or
miR-125a/b activity might provide a novel therapeutic approach for combined targeted drug administration.

\section{Additional files}

Additional file 1: Table S1. Gene fold changes in T47D cells transfected with HER2-3'UTR or control vector. (XLSX 891 kb)

Additional file 2: Table S2. Gene-set enrichment analysis in T47D cells transfected with HER2-3'UTR or control vector. (XLSX 37 kb)

Additional file 3: Table S3. Shared miRNAs binding sites prediction in human HER2 and HER4 3'UTR. (XLSX 12 kb)

Additional file 4: Table S4. miRNAs binding sites prediction in human HER2 and HER3 3'UTR. (XLSX 26 kb)

Additional file 5: Figure S1. Effect of trastuzumab on miR-125a/b levels. Real-time PCR analysis of miR-125a and miR-125b levels in AU565 cells treated with $10 \mu \mathrm{g} / \mathrm{ml}$ trastuzumab at the indicated times. Data were generated from three replicates. (PDF 295 kb)

Additional file 6: Figure S2. Effect of trastuzumab on HER2 and HER3 levels. FACS analysis of HER2 and HER3 levels in AU565 cells treated with $10 \mu \mathrm{g} / \mathrm{ml}$ trastuzumab at the indicated times or the indicated concentrations of trastuzumab. (PDF $1027 \mathrm{~kb}$ )

Additional file 7: Figure S3. Combinatory treatment with HER3 siRNA and trastuzumab is useful for overcoming trastuzumab resistance. (A-C) Real-time PCR (A), western blotting (B), and FACS (C) analysis of HER2 and HER3 expression in AU565 parental and trastuzumab-resistant (TtzmR) cell lines. (D) Proliferation of AU565 parental and TtzmR cells treated with $10 \mu \mathrm{g} / \mathrm{ml}$ trastuzumab or control lgG, along with a cholesterol-conjugated siRNA targeting HER3 or a randomized oligonucleotide (control). All error bars represent the standard deviation. All quantitative data were generated from a minimum of three replicates. (E, F) AU565 TtzmR cells were s.c. injected into female BALB/c-nude mice. Mice were treated with cholesterolconjugated HER3 siRNA or trastuzumab at days 0, 7, and 14. Representative in vivo luciferase images of mice at days 0,10 , and $21(E)$. The results are presented as means \pm SD from five mice. Immunostaining of HER3 in xenograft tumor sections (F). Red, HER3; Blue, DAPI. Scale bar, 40 m. (PDF 3149 kb)

Additional file 8: Figure S4. Correlation between miR-125a/b and EGFR family proteins in HER2 positive breast cancer patients. Correlation between miR-125a and miR-125b and EGFR family proteins (EGFR, HER2 and HER3) in HER2 positive breast cancer patients. (PDF $1450 \mathrm{~kb}$ )

Additional file 9: Figure S5. Reciprocal ceRNA activity between HER2 and HER3 3'UTR. HER2 3'UTR-luciferase reporter assay in T47D cells transfected with the HER3 3'UTR or control vector. (PDF 150 kb)

Additional file 10: Figure S6. Effect of trastuzumab on HER2 protein levels. Western blot analysis of HER2 levels in AU565 cells treated with the indicated concentrations of trastuzumab. Numbers below the blot indicates quantification shown on Western blot after normalization. (PDF $282 \mathrm{~kb}$ )

\section{Abbreviations}

3'UTR: 3'untranslated regions; CDS: Coding sequence; ceRNA: competitive endogenous RNA; FACS: Fluorescence-activated cell sorting; HER2: Human epidermal growth factor receptor 2; HER3: Human epidermal growth factor receptor 3; miRNAs: microRNAs; MREs: iRNA response elements; RISC: RNAinduced silencing complex; TCGA: The Cancer Genome Atlas;

TtzmR: Trastuzumab-resistant

\section{Acknowledgments}

We thank Fulian Liao and Lihong Zhou for providing technical help in culturing cells. We thank Tong Zhao for FACS sorting. We also thank Kuan $\mathrm{Li}$ and Xinqi Jiang for data analysis.

\section{Ethical approval}

The study of mice was in strict accordance with the regulations of the Institute of Microbiology, Chinese Academy of Sciences of Research Ethics Committee. The protocol was approved by the Research Ethics Committee (permit number PZIMCAS2011001). All animal experiments were performed 
in strict accordance with institutional guidelines on the handling of laboratory animals. Informed written consents were obtained from breast cancer patients involved in our study. The study protocol was approved by the Ethics Committee of the Cancer Institute and Hospital, Chinese Academy of Medical Sciences and the General Hospital of People's Liberation Army of China.

\section{Funding}

This work was supported by a grant from Major State Basic Research Development Program of China (973 Program) (No. 2014CB542602), the Strategic Priority Research Program of the Chinese Academy of Sciences (XDPB0304), One Belt and One Road International Science and Technology Cooperation of Chinese Academy of Sciences (153211KYSB20170001), and grants from the National Natural Science Foundation of China (81761128002, 81602339, 81621091, 81471960, 81672815).

\section{Availability of data and materials}

Please contact the corresponding author for all data requests. Raw data for microarray in this study are available through the Gene Expression Omnibus (GEO) via accession GSE102402.

\section{Authors' contributions}

SM designed experiments; $\mathrm{XL}, \mathrm{YX}$, and YD performed experiments; $\mathrm{HZ}$ and JW collected patient samples and clinical information; CL performed data analysis; and XL, YX and SM wrote the manuscript. All authors have read and approved the final manuscript.

\section{Consent for publication}

Written consent for publication was obtained from all the patients involved in our study.

\section{Competing interests}

The authors declare that they have no competing interests.

\section{Publisher's Note}

Springer Nature remains neutral with regard to jurisdictional claims in published maps and institutional affiliations.

\section{Author details}

${ }^{1}$ CAS Key Laboratory of Pathogenic Microbiology and Immunology, Institute of Microbiology, Chinese Academy of Sciences (CAS), Beijing, People's Republic of China. ${ }^{2}$ Cancer Institute and Hospital, Chinese Academy of Medical Sciences, Beijing, People's Republic of China. ${ }^{3}$ The General Hospital of People's Liberation Army, Beijing, People's Republic of China. ${ }^{4}$ University of Chinese Academy of Sciences, Beijing, People's Republic of China.

\section{Received: 14 December 2017 Accepted: 24 July 2018}

\section{Published online: 02 August 2018}

\section{References}

1. Higa GM, Singh V, Abraham J. Biological considerations and clinical applications of new HER2-targeted agents. Expert Rev Anticancer Ther 2010;10:1497-509.

2. Citri A, Yarden Y. EGF-ERBB signalling: towards the systems level. Nat Rev Mol Cell Biol. 2006;7:505-16.

3. Foley J, Nickerson NK, Nam S, Allen KT, Gilmore JL, Nephew KP, Riese DJ 2nd. EGFR signaling in breast cancer: bad to the bone. Semin Cell Dev Biol. 2010;21:951-60

4. Shi FM, Telesco SE, Liu YT, Radhakrishnan R, Lemmon MA. ErbB3/HER3 intracellular domain is competent to bind ATP and catalyze autophosphorylation. Proc Natl Acad Sci U S A. 2010;107:7692-7.

5. Bertelsen V, Stang E. The mysterious ways of ErbB2/HER2 trafficking. Membranes (Basel). 2014;4:424-46.

6. Zhang Y, Zhang J, Liu C, Du S, Feng L, Luan X, Zhang Y, Shi Y, Wang T, Wu $Y$, et al. Neratinib induces ErbB2 ubiquitylation and endocytic degradation via HSP90 dissociation in breast cancer cells. Cancer Lett. 2016;382:176-85.

7. Chaturvedi P, Singh AP, Chakraborty S, Chauhan SC, Bafna S, Meza JL, Singh PK, Hollingsworth MA, Mehta PP, Batra SK. MUC4 mucin interacts with and stabilizes the HER2 oncoprotein in human pancreatic cancer cells. Cancer Res. 2008;68:2065-70.
8. Li X, Sun L, Hou JW, Gui MM, Ying JM, Zhao H, Lv N, Meng SD. Cell membrane gp96 facilitates HER2 dimerization and serves as a novel target in breast cancer. Int J Cancer. 2015;137:512-24.

9. Wilks ST. Potential of overcoming resistance to HER2-targeted therapies through the PI3K/Akt/mTOR pathway. Breast. 2015;24:548-55.

10. Aksamitiene E, Kiyatkin A, Kholodenko BN. Cross-talk between mitogenic Ras/MAPK and survival PI3K/Akt pathways: a fine balance. Biochem Soc Trans. 2012;40:139-46.

11. Monteiro IDC, Madureira P, de Vasconscelos A, Pozza DH, de Mello RA. Targeting HER family in HER2-positive metastatic breast cancer: potential biomarkers and novel targeted therapies. Pharmacogenomics. 2015;16:257-71.

12. Menyhart O, Santarpia L, Gyorffy B. A comprehensive outline of Trastuzumab resistance biomarkers in HER2 overexpressing breast Cancer. Curr Cancer Drug Targets. 2015;15:665-83.

13. Ocana A, Vera-Badillo F, Seruga B, Templeton A, Pandiella A, Amir E. HER3 overexpression and survival in solid tumors: a meta-analysis. Jnci-Journal of the National Cancer Institute. 2013;105:266-73.

14. Dey N, Williams C, Leyland-Jones B, De P. A critical role for HER3 in HER2amplified and non-amplified breast cancers: function of a kinase-dead RTK. Am J Transl Res. 2015;7:733-50.

15. Green AR, Barros FFT, Abdel-Fatah TMA, Moseley P, Nolan CC, Durham AC, Rakha EA, Chan S, Ellis IO. HER2/HER3 heterodimers and p21 expression are capable of predicting adjuvant trastuzumab response in HER2+breast cancer. Breast Cancer Res Treat. 2014;145:33-44.

16. Garrett JT, Olivares MG, Rinehart C, Granja-Ingram ND, Sanchez V, Chakrabarty A, Dave B, Cook RS, Pao W, McKinely E, et al. Transcriptional and posttranslational up-regulation of HER3 (ErbB3) compensates for inhibition of the HER2 tyrosine kinase. Proc Natl Acad Sci U S A. 2011;108:5021-6.

17. Chakrabarty A, Sanchez V, Kuba MG, Rinehart C, Arteaga CL. Feedback upregulation of HER3 (ErbB3) expression and activity attenuates antitumor effect of PI3K inhibitors. Proc Natl Acad Sci U S A. 2012;109:2718-23.

18. Lipton A, Goodman L, Leitzel K, Cook J, Sperinde J, Haddad M, Kostler WJ, Huang WD, Weidler JM, Ali S, et al. HER3, p95HER2, and HER2 protein expression levels define multiple subtypes of HER2-positive metastatic breast cancer. Breast Cancer Res Treat. 2013;141:43-53.

19. Park YH, Jung HA, Choi MK, Chang W, Choi YL, Do IG, Ahn JS, Im YH. Role of HER3 expression and PTEN loss in patients with HER2-overexpressing metastatic breast cancer (MBC) who received taxane plus trastuzumab treatment. Br J Cancer. 2014;110:384-91.

20. Winter J, Jung S, Keller S, Gregory Rl, Diederichs S. Many roads to maturity: microRNA biogenesis pathways and their regulation. Nat Cell Biol. 2009;11: 228-34.

21. Newman MA, Hammond SM. Emerging paradigms of regulated microRNA processing. Genes Dev. 2010;24:1086-92.

22. Deng MM, Hou JW, Hu J, Wang S, Chen M, Chen LZ, Ju Y, Li CF, Meng SD Hepatitis B virus mRNAs functionally sequester let-7a and enhance hepatocellular carcinoma. Cancer Lett. 2016;383:62-72.

23. Karreth FA, Reschke M, Ruocco A, Ng C, Chapuy B, Leopold V, Sjoberg M, Keane TM, Verma A, Ala U, et al. The BRAF pseudogene functions as a competitive endogenous RNA and induces lymphoma in vivo. Cell. 2015;161:319-32.

24. Ferracin M, Bassi C, Pedriali M, Pagotto S, D'Abundo L, Zagatti B, Corra F, Musa G, Callegari E, Lupini L, et al. miR-125b targets erythropoietin and its receptor and their expression correlates with metastatic potential and ERBB2/HER2 expression. Mol Cancer. 2013;12(1):130.

25. Ala U, Karreth FA, Bosia C, Pagnani A, Taulli R, Leopold V, Tay Y, Provero P, Zecchina R, Pandolfi PP. Integrated transcriptional and competitive endogenous RNA networks are cross-regulated in permissive molecular environments. Proc Natl Acad Sci U S A. 2013;110:7154-9.

26. Seo AN, Kwak Y, Kim DW, Kang SB, Choe G, Kim WH, Lee HS. HER2 status in colorectal Cancer: its clinical significance and the relationship between HER2 gene amplification and expression. PLoS One. 2014;9(5):e98528.

27. Citri A, Skaria KB, Yarden Y. The deaf and the dumb: the biology of ErbB-2 and ErbB-3. Exp Cell Res. 2003;284:54-65.

28. Scott GK, Goga A, Bhaumik D, Berger CE, Sullivan CS, Benz CC. Coordinate suppression of ERBB2 and ERBB3 by enforced expression of micro-RNA miR125a or miR-125b. J Biol Chem. 2007;282:1479-86.

29. He J, Xu Q, Jing Y, Agani F, Qian X, Carpenter R, Li Q, Wang XR, Peiper SS, Lu ZM, et al. Reactive oxygen species regulate ERBB2 and ERBB3 expression via miR-199a/125b and DNA methylation. EMBO Rep. 2012;13:1116-22.

30. Mukherjee A, Badal Y, Nguyen XT, Miller J, Chenna A, Tahir H, Newton A, Parry G, Williams S. Profiling the HER3/PI3K pathway in breast tumors using 
proximity-directed assays identifies correlations between protein complexes and phosphoproteins. PLoS One. 2011;6(1):e16443.

31. Cook RS, Garrett JT, Sanchez V, Stanford JC, Young C, Chakrabarty A, Rinehart C, Zhang YX, Wu YM, Greenberger L, et al. ErbB3 ablation impairs PI3K/Akt-dependent mammary tumorigenesis. Cancer Res. 2011;71:3941-51.

32. Novotny CJ, Pollari S, Park JH, Lemmon MA, Shen WJ, Shokat KM. Overcoming resistance to HER2 inhibitors through state-specific kinase binding. Nature Chemical Biology. 2016;12:923.

33. Koutras A, Kotoula V, Kouvatseas G, Christodoulou C, Pectasides D, Batistatou A, Bobos M, Tsolaki E, Papadopoulou K, Pentheroudakis G, et al. Evaluation of the association of HER family members with efficacy of trastuzumab therapy in metastatic breast cancer. Ann Oncol. 2016;27:15-42. https://doi.org/10.1093/annonc/mdw363.52.

34. Zhu CH, Domann FE. Dominant negative interference of transcription factor AP-2 causes inhibition of ErbB-3 expression and suppresses malignant cell growth. Breast Cancer Res Treat. 2002;71:47-57.

35. Iorio MV, Casalini P, Piovan C, Di Leva G, Merlo A, Triulzi T, Menard S, Croce CM, Tagliabue E. microRNA-205 regulates HER3 in human breast Cancer. Cancer Res. 2009;69:2195-200.

36. Bischoff A, Bayerlova M, Strotbek M, Schmid S, Beissbarth T, Olayioye MA. A global microRNA screen identifies regulators of the ErbB receptor signaling network. Cell Communication and Signaling. 2015;13(1):5.

37. Yan X, Chen X, Liang HW, Deng T, Chen WX, Zhang SY, Liu MH, Gao XJ, Liu $Y Q$, Zhao CH, et al. miR-143 and miR-145 synergistically regulate ERBB3 to suppress cell proliferation and invasion in breast cancer. Mol Cancer. 2014; 13(1):220.

38. Yu J, Li Q, Xu Q, Liu L, Jiang B. MiR-148a inhibits angiogenesis by targeting ERBB3. J Biomed Res. 2011;25:170-7.

39. Berghoff AS, Bartsch R, Preusser M, Ricken G, Steger GG, Bago-Horvath Z, Rudas M, Streubel B, Dubsky P, Gnant M, et al. Co-overexpression of HER2/ HER3 is a predictor of impaired survival in breast cancer patients. Breast. 2014:23:637-43.

40. Marty M, Cognetti F, Maraninchi D, Snyder R, Mauriac L, Tubiana-Hulin M, Chan S, Grimes D, Anton A, Lluch A, et al. Randomized phase II trial of the efficacy and safety of trastuzumab combined with docetaxel in patients with human epidermal growth factor receptor 2-positive metastatic breast cancer administered as first-line treatment: the M77001 study group. J Clin Oncol. 2005;23:4265-74.

41. Arteaga CL, Sliwkowski MX, Osborne CK, Perez EA, Puglisi F, Gianni L. Treatment of HER2-positive breast cancer: current status and future perspectives. Nat Rev Clin Oncol. 2012;9:16-32.

42. Madrid-Paredes A, Canadas-Garre M, Sanchez-Pozo A, Calleja-Hernandez M. Non-HER2 signaling pathways activated in resistance to anti-HER2 therapy in breast cancer. Breast Cancer Res Treat. 2015;153:493-505.

43. Cha Y, Han SW, Seol H, Oh DY, Im SA, Bang YJ, Park IA, Han W, Noh DY, Kim TY. Immunohistochemical features associated with sensitivity to Lapatinibplus-Capecitabine and resistance to Trastuzumab in HER2-positive breast Cancer. Anticancer Res. 2014;34:4275-80.

44. Kunii K, Davis L, Gorenstein J, Hatch H, Yashiro M, Di Bacco A, Elbi C, Lutterbach B. FGFR2-amplified gastric cancer cell lines require FGFR2 and Erbb3 signaling for growth and survival. Cancer Res. 2008:68:2340-8.

45. Engelman JA, Zejnullahu K, Mitsudomi T, Song YC, Hyland C, Park JO, Lindeman N, Gale CM, Zhao XJ, Christensen J, et al. MET amplification leads to gefitinib resistance in lung cancer by activating ERBB3 signaling. Science. 2007:316:1039-43.

46. Ishizawar RC, Miyake T, Parsons SJ. c-Src modulates ErbB2 and ErbB3 heterocomplex formation and function. Oncogene. 2007;26:3503-10.

47. Hodeib M, Serna-Gallegos T, Tewari KS. A review of HER2-targeted therapy in breast and ovarian cancer: lessons from antiquity - CLEOPATRA and PENELOPE. Future Oncol. 2015;11:3113-31.

48. Agus DB, Akita RW, Fox WD, Lewis GD, Higgins B, Pisacane PI, Lofgren JA, Tindell C, Evans DP, Maiese K, et al. Targeting ligand-activated ErbB2 signaling inhibits breast and prostate tumor growth. Cancer Cell. 2002;2: $127-37$

49. Baselga J, Cortes J, Kim SB, Im SA, Hegg R, Im YH, Roman L, Pedrini JL, Pienkowski T, Knott A, et al. Pertuzumab plus Trastuzumab plus docetaxel for metastatic breast Cancer. N Engl J Med. 2012;366:109-19.

50. Lakshmanan I, Seshacharyulu P, Haridas D, Rachagani S, Gupta S, Joshi S, Guda C, Yan Y, Jain M, Ganti AK, et al. Novel HER3/MUC4 oncogenic signaling aggravates the tumorigenic phenotypes of pancreatic cancer cells. Oncotarget. 2015;6:21085-99.

\section{Ready to submit your research? Choose BMC and benefit from}

- fast, convenient online submission

- thorough peer review by experienced researchers in your field

- rapid publication on acceptance

- support for research data, including large and complex data types

- gold Open Access which fosters wider collaboration and increased citations

- maximum visibility for your research: over $100 \mathrm{M}$ website views per year

At BMC, research is always in progress.

Learn more biomedcentral.com/submissions 